\title{
Mobile health applications in self- management of patients with chronic obstructive pulmonary disease: a systematic review and meta-analysis of their efficacy
}

\author{
Fen Yang ${ }^{1 \dagger}$, Yuncui Wang ${ }^{1 \dagger}$, Chongming Yang ${ }^{2}$, Hui Hu ${ }^{1 *}$ and Zhenfang Xiong ${ }^{1 *+}$
}

\begin{abstract}
Background: Mobile health applications are increasingly used in patients with Chronic Obstructive Pulmonary Disease (COPD) to improve their self-management, nonetheless, without firm evidence of their efficacy. This meta-analysis was aimed to assess the efficacy of mobile health applications in supporting self-management as an intervention to reduce hospital admission rates and average days of hospitalization, etc.

Methods: PubMed, Web of Science (SCI), Cochrane Library, and Embase were searched for relevant articles published before November 14th, 2017. A total of 6 reports with randomized controlled trials (RCTs) were finally included in this meta-analysis.

Results: Patients using mobile phone applications may have a lower risk for hospital admissions than those in the usual care group (risk ratio $(\mathrm{RR})=0.73,95 \% \mathrm{Cl}[0.52,1.04]$ ). However, there was no significant difference in reducing the average days of hospitalization.
\end{abstract}

Conclusion: Self-management with mobile phone applications could reduce hospital admissions of patients with COPD.

Keywords: Chronic obstructive pulmonary disease, Self-management, Hospital admissions, Mobile applications

\section{Background}

Chronic Obstructive Pulmonary Disease (COPD) is a major global chronic disease which affected millions of people worldwide [1], causing considerable hospital admissions. The World Health Organization (WHO) has estimated that COPD which causes considerable hospital admission will become the third cause of global deaths by 2020 [2-5]. These patients are heavy users of healthcare and social service resources [6,7]. As there is currently no cure for COPD, appropriate self-care and management may play an important role in the patients' lifetime. Self-management techniques, such as adherence

\footnotetext{
* Correspondence: xiong_zhenfang@126.com; xiong_zhenfang@126.com ${ }^{\dagger}$ Fen Yang, Yuncui Wang and Zhenfang Xiong contributed equally to this work.

${ }^{1}$ School of Nursing, Hubei University of Chinese Medicine, Wuhan, China Full list of author information is available at the end of the article
}

to medication, exercises, and prompt medical care, are crucial to improve the health status and have the potential to reduce hospital admissions [8-11].

Mobile health (mHealth), is now widely used for self-management of COPD, a term used to describe medical practice and healthcare in support of mobile computing and mobile devices (such as tablets, mobile phones, etc.). However, it is unclear whether these applications are beneficial to patients [12]. The deployment of eHealth applications is conducive to the availability of health care, which in turn enhances the patient's understanding of his illness, sense of control, and willingness to manage himself [13]. However, cheaper and widely available mobile phones are not other specialized medical devices. Mobile phones with applications to monitor, prompt, and record health behaviors have become a feasible and acceptable intervention [14]. Some reviews 
reported that mHealth applications were effective in promoting disease self-management and daily lifestyle changes [15-17]. Several studies showed that mobile phones could deliver effective behavior change interventions and had many positive evidences [9, 18-20]. Mobile phones were also found effective in promoting COPD patients' physical activity and exercise capacity [21]. However, another study found that COPD patients with telephone-based care had greater mortality than usual care [22]. It is not clear how effectively mobile phone interventions could improve hospital admissions and lengths of hospitalization of COPD patients. Therefore, this study was aimed to compare the efficacy of mobile phone intervention with usual care in self-management, in terms of hospital admissions and the lengths of hospitalization.

\section{Methods}

\section{Data sources and searches}

A literature search without language restriction was performed using PubMed, Web of Science, the Cochrane Library, and Embase databases to identify potentially eligible studies published prior to November 14, 2017. All titles, keywords, and abstracts were examined in accordance with our search criteria. Full reports also were reviewed in case of uncertainty. In addition, references of retrieved studies and review articles were also manually checked to identify additional relevant studies. Some authors were even contacted for further information.

\section{Study selection}

Each study had to meet four criteria to be included in this study. First, studies were RCTs reported in full text with a title and abstract. Second, it included adults with a clinical diagnosis of COPD and compare mobile phone application interventions with the control group in usual care only (namely, routine or standard care). Third, telemonitoring studies entailed a self-management by COPD patients with $\geq 1$ month follow-up. Fourth, the trials evaluated at least one of the following primary or secondary outcomes. The primary outcome was a hospital admission. The secondary outcome was the length of hospitalization, activity level, and lung function (e.g., predicted FEV1 percentage). Inclusion of each study was evaluated and determined independently by two reviewers. Exclusion criteria included: (1) reports based on systematic reviews and meta-analyses; (2) mobile-based interventions only via phone calls or sending messages.

\section{Data extraction and quality assessment}

From the articles that met the inclusion criteria, two reviewers independently extracted descriptions of the objectives, design, participants, interventions, and followup time. Any disagreements in data extraction were resolved by a discussion among the reviewers, and a final decision was made by another reviewer. If it is difficult or unclear to extract data from an article, its author was directly contacted to request the original data.The Cochrane Group's predesigned table [23] was used to assess the quality of the studies, including randomization, allocation concealment, similarity of baseline, criteria of inclusion/exclusion, blinding of participants and researchers, blinding of assessors, attrition rates, reporting of lost participants, and other sources of biases. Studies were scored one point for each fulfilled criterion. The quality of the studies was divided into three levels: low ( $\leq 3$ points), moderate (4-6 points), and high (7-9 points).

\section{Data synthesis and analysis}

Eight studies were selected for the systematic review [24-31] and six of that were included for the meta-analysis with a random-effects model [24-29]. The outcomes reported by similar multiple studies were combined for the analysis. Also, meta-analyzed were the RCTs that reported the number of readmissions and the average days of hospitalization of each group (usual care vs. eHealth).

Data were obtained from the original selected studies or calculated [32] from the raw data. Risk ratios (RRs) were calculated for hospital admissions and mortality rates. Statistical heterogeneity was measured with the chi-square $\left(\chi^{2}\right)$ and $I^{2}$ statistics whose values greater than $50 \%$ indicate a high heterogeneity for the latter [33]. Publication bias was depicted with Begg's plot. Standard Mean Differences (SMD) were estimated with random effects modeling. All analyses were performed using Stata 12.0.

\section{Results}

\section{Basic characteristics of the studies}

From the 4072 potentially relevant reports initially identified, 3350 publications were excluded. The remainder of 722 retrieved reports were selected for full-text assessments and detailed evaluations. Finally, eight articles fulfilled our inclusion criteria [24-31] and only six articles were included in our meta-analysis [24-29] because two didn't report the patients' hospital admission [30, 31]. Figure 1 shows the literature flow diagram. We also extracted some additional information, such as country, mean age, the sample size of each group, sex, FEV1, the intervention methods, the length of follow-up and BMI, as shown in Table 1. Most RCTs compared a continued care with a usual care. Six RCTs reported the primary outcome of hospital admissions [24-29]. Only one study was a multicenter RCTs, and the others were conducted in single centers. There were totally 391 participants with COPD, 
Records identified through database

searching

$(n=6216)$

PUBMED: 526

EMBASE: 2310

SCl: 2348

Cochrane library: 1032
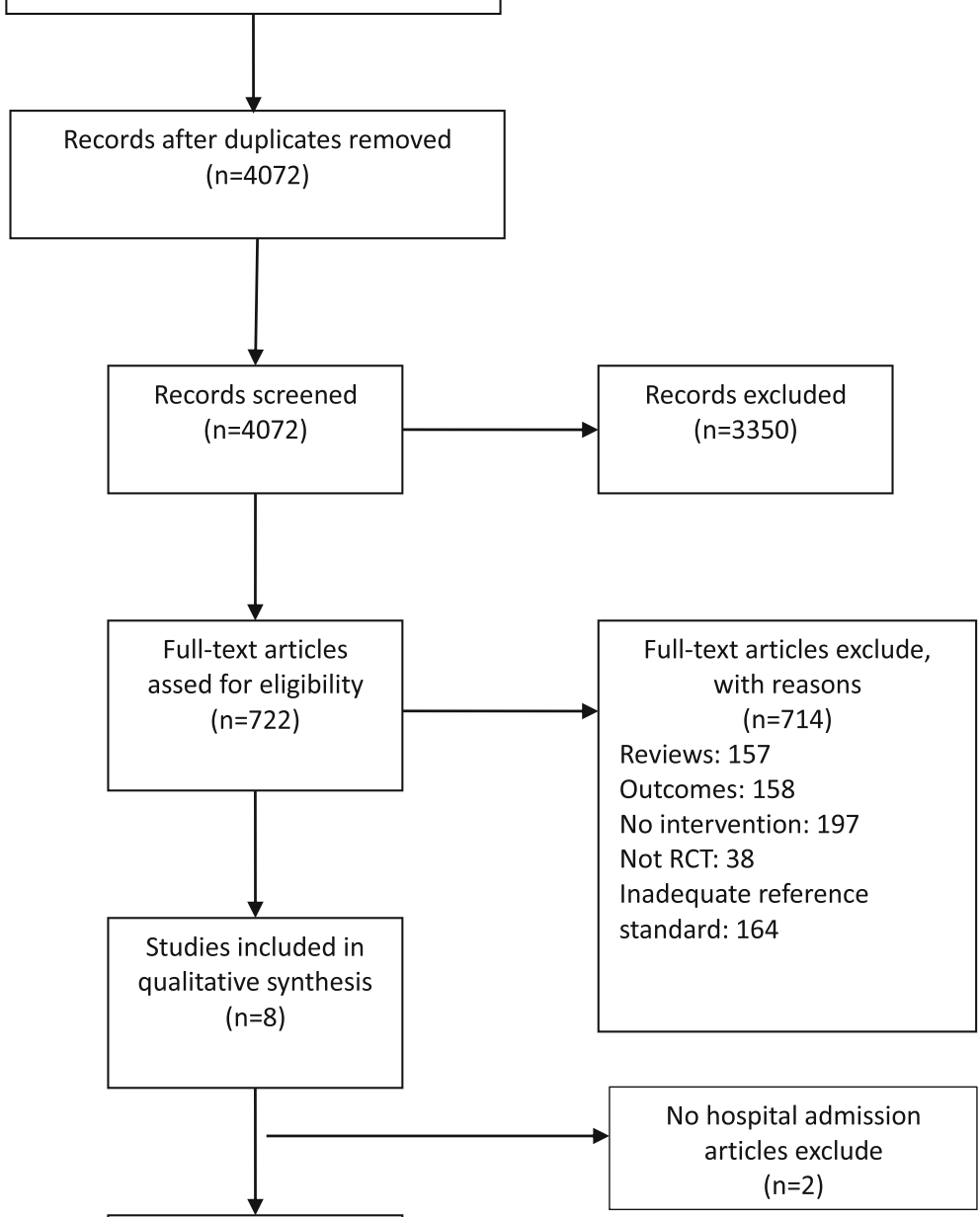

Studies included in quantitative synthesis

(Meta-analysis $\mathrm{n}=6$ )

Fig. 1 Summary of Evidence Search and Publication Selection

293 (74.9\%) of whom were men. The participants in one study had additional heart failures [27]. The sample sizes of subjects ranged from 24 to 99 . There were six studies reporting the duration of the intervention equal or more than 6 months. The age of participants ranged from 63.5 to 81.0 years. The lung dysfunction was indicated by FEV1 (\% predicted) that ranged from 37.9 to $58.9 \%$. BMI ranged from 23.2 to $28.8 \mathrm{~kg} / \mathrm{m}^{2}$. Follow-ups were conducted for a range of 1 to 12 months and a mean of 6.9 months.
The intervention of the five studies included mobile/ smartphones with different software (Phone-personal digital assistant, MMA400, HTC P3600/3700, Sony Ericsson K600i, and HTC Desire S) and measuring devices. Applications were installed on smartphones to support patients in recording and monitoring their own physiological status, such as oxygen saturation levels, pulse rates, pedometers, or blood pressure monitors; or health behaviors, such as medications and dietary intake and exercise levels. Patients uploaded the data to their phones and sent 


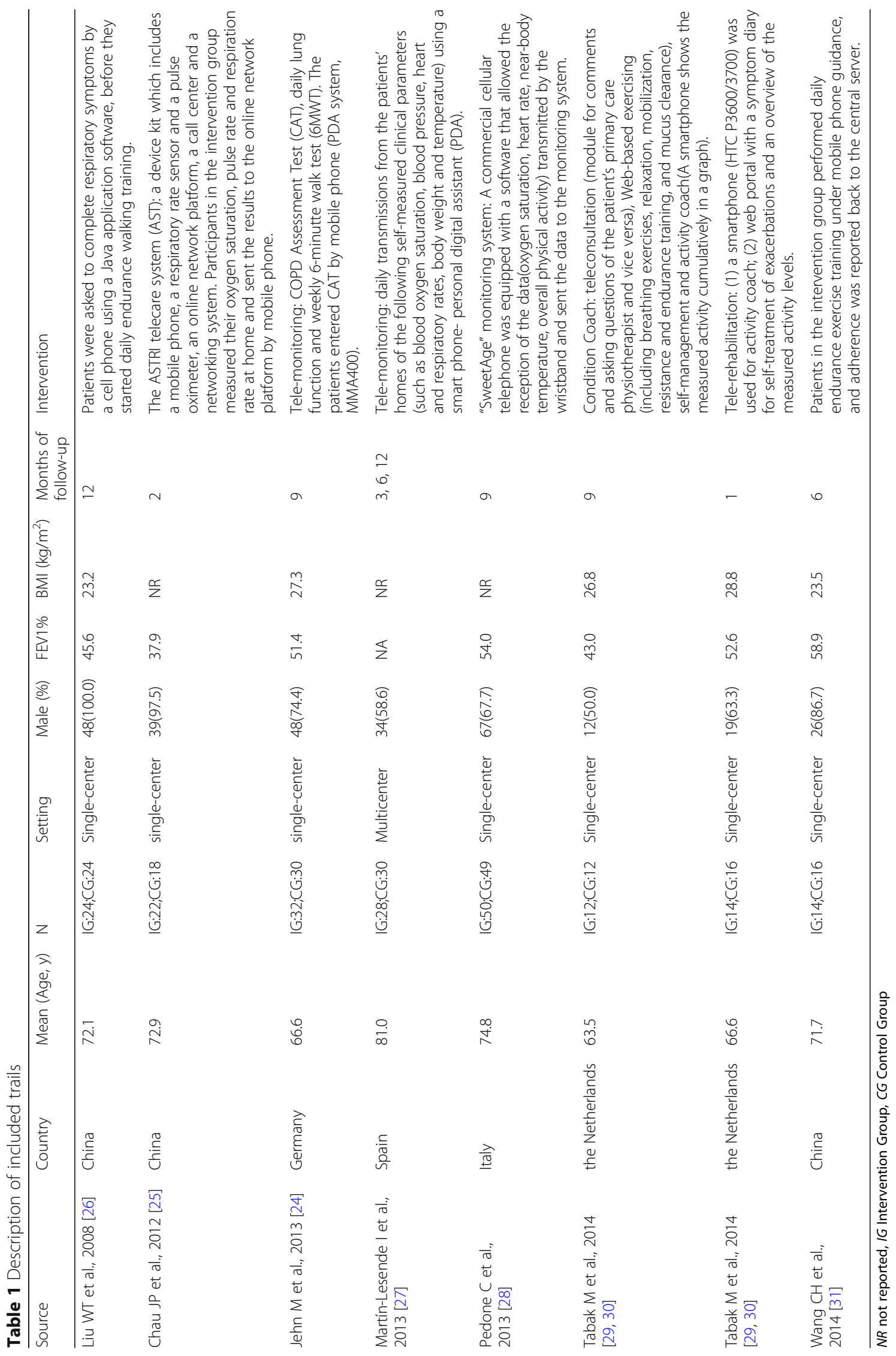


the data to the networking/monitoring systems for healthcare providers to follow up and personalize feedbacks. The aim of the intervention was to train patients and promote self-monitoring and healthy lifestyle behaviors. In three of all the trials, the mobile/smartphone was used to coach activities. The patients in control groups received usual care.

\section{Study quality and publication Bias}

The overall quality of the studies (Table 2) was moderate to high (4-7 scores). Five studies scored less than or equal to 6, and three studies scored less than 9. The most common reason for lower scores was the absence of a double-blind procedure, which was impossible due to the nature of the intervention. The assessors were not blinded to the outcomes in all the studies (100.0\%) and researchers/participants were not blinded in 6 studies (75.0\%). Only one study (12.5\%) did not report the characteristics of participants lost for follow-ups. Begg's plot that was used to examine publication bias showed that there was no evident publication bias $(p=1.00)$.

\section{Hospital admission rates}

Figure 2 presented our meta-analyses and RR calculations of RCTs reported hospital admission. Six studies [24-29] assessed the effect of mobile health applications on hospital admission. As Martín-Lesende [27] reported the data of patients at the follow-up of 3 months, 6 months, and 12 months, we treated it as three separate experiments in our meta-analysis. We found that a lower risk for hospital admission among patients using mobile phone applications than that of the usual care group $(\mathrm{RR}=0.73$ [95\% CI, 0.52 to 1.04$])$. The study by Jehn $\mathrm{M}$ [24] found that the hospital admission rates decreased significantly (RR, 0.30 [95\% CI, 0.15 to 0.59]). But the heterogeneity in the overall pooled effect is $51.4 \%\left(\mathrm{I}^{2}\right.$ $=51.4 \%, p=0.04)$, implying that effect sizes varied across studies.

\section{Average days of hospitalization}

As shown in Fig. 3, six studies reported the average days of hospital stays. No significant difference was found between the intervention group and control group (SMD -0.06 [95\% CI, -0.31 to 0.18$]$ ).

\section{Other results}

Five articles reported that phone-based system could significantly improve exercise capacity and activity levels [24, 26, 29-31]. One study showed a significant reduction (lower predicted FEV1 percentage) in lung function of tele-monitoring intervention groups [24]. However, there was no significant differences found in another study [26].

\section{Sensitivity analysis}

A sensitivity analysis was performed for the primary outcome to test an overall pooled effect. The results were no different between fixed and random statistical effects ( RR $=0.73 ; P=0.000)$. The effect of sequentially omitting a low-quality study [24] and recalculating the pooled estimates for the remaining studies did not significantly alter the effect on all cause readmission ( $R R=0.73$ vs. $0.83 ; P=0.000)$.

\section{Discussion}

Our results showed that mobile phone-based health applications in self-management currently could reduce hospital admissions of patients with COPD and could improve exercise capacity and activity levels, but could not reduce the average days of hospitalization.

Our findings were slightly different from another telemonitoring study which used a touch screen telemonitoring equipment to record and transmit a daily questionnaire about symptoms and corresponding treatment, and did not provide any convincing evidence of effectiveness on hospital admission and the duration of admissions [34]. The inconsistence may be due to the difference between screen telemonitoring and mobile phone. Mobile phone-based applications were found easy to learn and use by the participants as well as the patients with COPD. Mobile phone-based health applications could be practically more feasible as an intervention. Some studies reported they were a simple, reliable, easy to perform, and cost-saving intervention in behavior-changes, with advantages like adherence and intensity of the interventions, and more willingness of patients to use than other electronic devices $[35,36]$. In addition, the virtual link created by sending self-monitoring data to a research nurse provided patients with a sense of continuity of care [37].

Mobile-phone-based system provides a feasible, efficient exercise training in improving exercise capacity, which was similar with other studies [38, 39]. Patients with COPD have decreased exercise capacity in their daily activities and they may have an inactive lifestyle [40-43]. Mobile phone applications, as a feasible and acceptable method for patients with COPD, can increase the capacity of self-management and the exercise adherence [44]. This result was similar with another review which evaluated the effectiveness of interventions delivered by computer and by mobile technology versus face-to-face or hard copy/digital documentary-delivered interventions [45]. A recent systematic review reported that mobile-based exercise programs could improve exercise capacity in patients with COPD in short and long term [30].

There are several limitations of our study. First, most RCTs compared an intervention with "usual care" whose details were not reported. Second, we only selected studies that reported the proportion of hospital admitted 


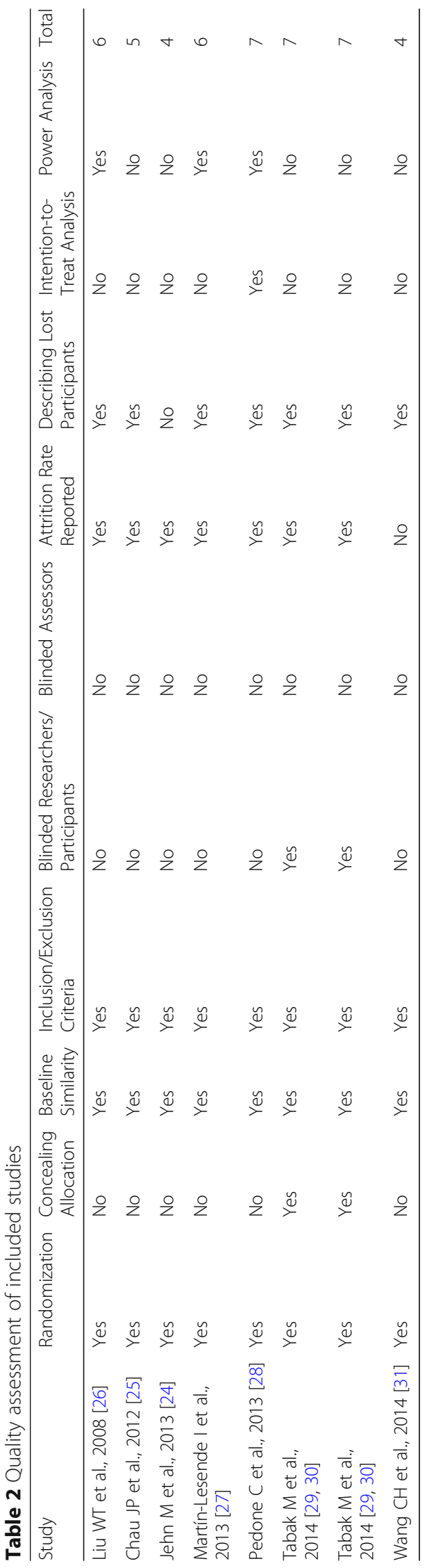




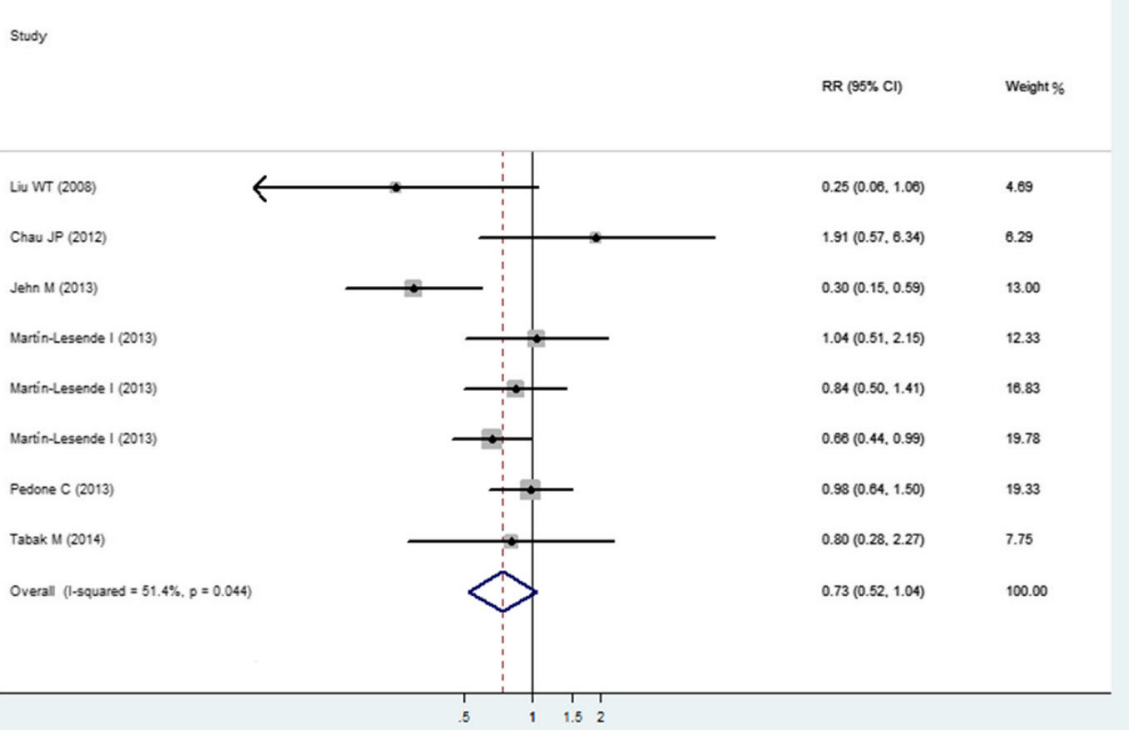

Fig. 2 Hospital admission for Intervention Group Compared with Control Group. Weights were from the random effects analysis

patients, but ignored information about secondary outcomes such as costs. Third, only eight studies were included in this systematic review and 6 studies in meta-analysis, most interventions were performed in short terms which could have influenced the results. Mobile phones will continue to evolve and are expected to be robust ubiquitous devices in the future, and researchers may think about how mobile phones can be used in future self-management of chronic disease. With the development of information technology and the expansion of mobile applications in medicine, we could improve the designs and clarify the effects of mobile health applications interventions for reducing hospital admission in patients with COPD in the future.

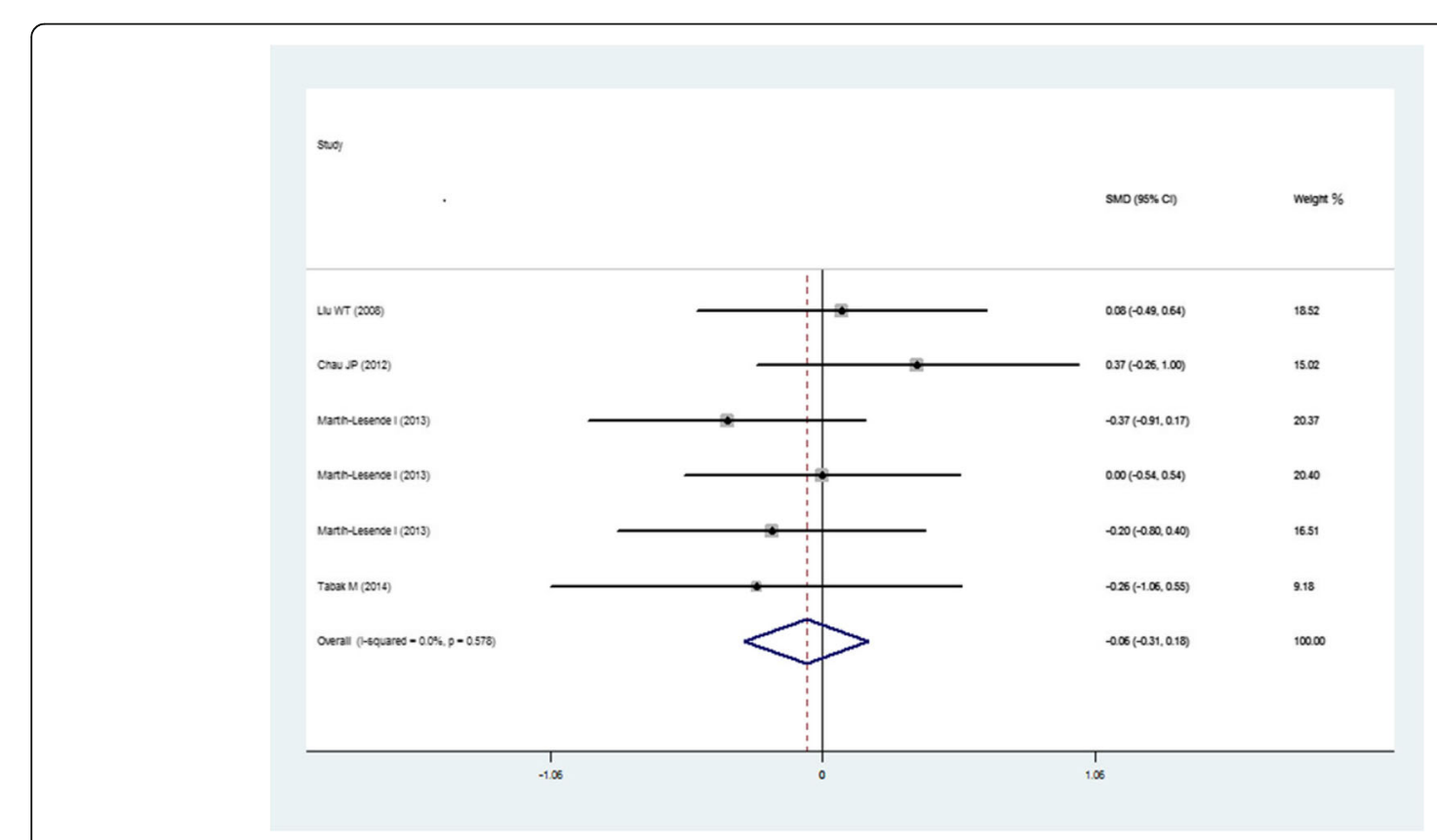

Fig. 3 Average hospital staying days for Intervention Group Compared with Control Group. Weights are from the random effects analysis 


\section{Conclusions}

The effectiveness of self-management with mobile or smart phones may help to reduce hospital admissions or improve health status of patients with COPD. Mobile phone with convenient applications have a great potential to minimize health problems and improve healthcare delivery.

\section{Abbreviations}

COPD: Chronic obstructive pulmonary disease; mHealth: Mobile health; RCTs: Randomized controlled trials; RRs: Risk ratios; SCl: Web of science

\section{Availability of data and materials}

The datasets used and/or analyzed during the current study are available from the corresponding author on reasonable request.

\section{Authors' contributions}

YF preformed the work of design, acquisition of data and drafting the manuscript WYC acquitted the data and wrote part of article; YCM and XZF analysed the data; $\mathrm{HH}$ conceived the report and wrote the manuscript. All the authors have read and approved the final manuscript.

\section{Ethics approval and consent to participate} Not applicable.

\section{Consent for publication}

Not applicable.

\section{Competing interests}

The authors declare that they have no competing interests.

\section{Publisher's Note}

Springer Nature remains neutral with regard to jurisdictional claims in published maps and institutional affiliations.

\section{Author details}

${ }^{1}$ School of Nursing, Hubei University of Chinese Medicine, Wuhan, China

${ }^{2}$ Research Support Center, Brigham Young University, Provo, UT, USA.

Received: 2 April 2018 Accepted: 12 June 2018

Published online: 04 September 2018

\section{References}

1. Global initial for chronic obstructive lung disease: Gloable strategy for the diagnosis, management, and prevention of chronic obstructive pulmonary disease (2017 report). Retrieved on August 1, 2018 at https://goldcopd.org/ gold-2017-global-strategy-diagnosis-management-prevention-copd/.

2. Puhan MA, Scharplatz M, Troosters T, Steurer J. Respiratory rehabilitation after acute exacerbation of COPD may reduce risk for readmission and mortality - a systematic review. Respir Res. 2005:6(1):54.

3. Mannino DM, Buist AS. Global burden of COPD: risk factors, prevalence, and future trends. Lancet. 2007:370(9589):765-73.

4. Lopez AD, Shibuya K, Rao C, Mathers CD, Hansell AL, Held LS, et al. Chronic obstructive pulmonary disease: current burden and future projections. Eur Respir J. 2006;27(2):397-412.

5. Buist AS, McBurnie MA, Vollmer WM, Gillespie S, Burney P, Mannino DM, et al. International variation in the prevalence of COPD (the BOLD study): a population-based prevalence study. Lancet. 2007;370(9589):741-50.

6. Mapel DW, McMillan GP, Frost FJ, Hurley JS, Picchi MA, Lydick E, et al. Predicting the costs of managing patients with chronic obstructive pulmonary disease. Respir Med. 2005;99(10):1325-33.

7. Tynan AJ, Lane SJCOPD. IIIness severity, resource utilization and cost. Ir Med J. 2005:98(2):41-2

8. Efraimsson EO, Hillervik C, Ehrenberg A. Effects of COPD self-care management education at a nurse-led primary health care clinic. Scand J Caring Sci. 2008;22(2):178-85.

9. Bourbeau J, Julien M, Maltais F, Rouleau M, Beaupré A, Bégin R, et al. Reduction of hospital utilization in patients with chronic obstructive pulmonary disease: a disease-specific self-management intervention. Arch Intern Med. 2003;163(5):585-91.

10. Zwerink M, Brusse-Keizer M, Van PD ZGA, Monninkhof EM, van der Palen J, et al. Self-management for patients with chronic obstructive pulmonary disease. Cochrane Database Syst Rev. 2014;3(3):CD002990.

11. Warwick M, Gallagher R, Chenoweth L, Stein-Parbury J. Self-management and symptom monitoring among older adults with chronic obstructive pulmonary disease. J Adv Nurs. 2010;66(4):784-93.

12. Black AD, Car J, Pagliari C, Anandan C, Cresswell K, Bokun T, et al. The impact of eHealth on the quality and safety of health care: a systematic overview. PLOS Med. 2011:8(1):e1000387.

13. Boulos MN, Brewer AC, Karimkhani C, Buller DB, Dellavalle RP. Mobile medical and health apps: state of the art, concerns, regulatory control and certification. Online J Public Health Inform. 2014;5(3):229.

14. Nguyen HQ, Wolpin S, Chiang KC, Cuenco D, Carrieri- Kohlman V. Exercise and symptom monitoring with a mobile device. AMIA Annu Symp Proc. 2006;1047

15. Nour M, Chen J, Allman-Farinelli M. Efficacy and external validity of electronic and mobile phone-based interventions promoting vegetable intake in young adults: systematic review and meta-analysis. J Med Internet Res. 2016;18(4):e58.

16. Devi BR, Syed-Abdul S, Kumar A, labal U, Nguyen PA, Li YC, et al. An updated systematic review with a focus on HIV/AIDS and tuberculosis long term management using mobile phones. Comput Methods Prog Biomed. 2015:122(2):257-65

17. Cui M, Wu X, Mao J, Wang X, Nie M. T2DM self-management via smartphone applications: a systematic review and meta-analysis. PLoS One. 2016;11(11):e0166718.

18. Hurling R, Catt M, Boni MD, Fairley BW, Hurst T, Murray P, et al. Using internet and mobile phone technology to deliver an automated physical activity program: randomized controlled trial. J Med Internet Res. 2007:9(2):e7.

19. Brendryen $H$, Drozd F, Kraft P. A digital smoking cessation program delivered through internet and cell phone without nicotine replacement (happy ending): randomized controlled trial. J Med Internet Res. 2008;10(5):e51.

20. Wennberg DE, Marr A, Lang L, O'Malley S, Bennett G. A randomized trial of a telephone care-management strategy. N Engl J Med. 2010;363(13):1245-55.

21. Martínez-García MDM, Ruiz-Cárdenas JD, Rabinovich RA. Effectiveness of smartphone devices in promoting physical activity and exercise in patients with chronic obstructive pulmonary disease: a systematic review. COPD. 2017:14(5):543-51.

22. Polisena J, Tran K, Cimon K, Hutton B, McGill S, Palmer K, et al. Home telehealth for chronic obstructive pulmonary disease: a systematic review and meta-analysis. J Telemed Telecare. 2010;16(3):120-7.

23. Higgins J, Green S. Cochrane Handbook for Systematic Reviews of Interventions. Chichester: J Wiley; 2006

24. Jehn M, Donaldson G, Kiran B, Liebers U, Mueller K, Scherer D, et al. Telemonitoring reduces exacerbation of COPD in the context of climate change-a randomized controlled trial. Environ Health. 2013:12:99.

25. Chau JP, Lee DT, Yu DS, Chow AY, Yu WC, Chair SY, et al. A feasibility study to investigate the acceptability and potential effectiveness of a telecare service for older people with chronic obstructive pulmonary disease. Int J Med Inform. 2012:81(10):674-82.

26. Liu WT, Wang CH, Lin HC, Lin SM, Lee KY, Lo YL, et al. Efficacy of a cell phone-based exercise programme for COPD. Eur Respir J. 2008;32(3):651-9.

27. Martín-Lesende I, Orruño E, Bilbao A, Vergara I, Cairo MC, Bayón JC, et al. Impact of telemonitoring home care patients with heart failure or chronic lung disease from primary care on healthcare resource use (the TELBIL study randomised controlled trial). BMC Health Serv Res. 2013:13:118.

28. Pedone C, Chiurco D, Scarlata S, Incalzi RA. Efficacy of multiparametric telemonitoring on respiratory outcomes in elderly people with COPD: a randomized controlled trial. BMC Health Serv Res. 2013;13:82.

29. Tabak M, Brusse-Keizer M, van der Valk P, Hermens H, Vollenbroek-Hutten M A telehealth program for self-management of COPD exacerbations and promotion of an active lifestyle: a pilot randomized controlled trial. Int $J$ Chron Obstruct Pulmon Dis. 2014:9:935-44.

30. Tabak M, Vollenbroek-Hutten MM, van der Valk PD, van der Palen J, Hermens HJ. A telerehabilitation intervention for patients with chronic obstructive pulmonary disease: a randomized controlled pilot trial. Clin Rehabil. 2014:28(6):582-91.

31. Wang CH, Chou PC, Joa WC, Chen LF, Sheng TF, Ho SC, et al. Mobilephone-based home exercise training program decreases systemic inflammation in COPD: a pilot study. BMC Pulm Med. 2014;14:142. 
32. Borenstein M, Hedges LV, Higgins JP, Rothstein HR. A basic introduction to fixed-effect and random-effects models for meta-analysis. Res Synth Methods. 2010;1(2):97-111.

33. Higgins JP, Thompson SG, Deeks JJ, Altman DG. Measuring inconsistency in meta-analyses. BMJ. 2003;327(7414):557-60.

34. Pinnock H, Hanley J, McCloughan L, Todd A, Krishan A, Lewis S, et al. Effectiveness of telemonitoring integrated into existing clinical services on hospital admission for exacerbation of chronic obstructive pulmonary disease: researcher blind, multicenter, randomized controlled trial. BMJ. 2013;347:f6070.

35. Kobayashi M, Hiyama A, Miura T, Asakawa C, Hirose M, Ifukube T. Elderly user evaluation of mobile touchscreen interactions. Springer Berlin Heidelberg. 2011;6946:83-99.

36. Velardo C, Shah SA, Gibson O, Clifford G, Heneghan C, Rutter H, et al. Digital health system for personalised COPD long-term management. BMC Med Inform Decis Mak. 2017;17(1):19.

37. Abaza H, Marschollek M. mHealth application areas and technology combinations. A comparison of literature from high and low/middle income countries. Methods Inf Med. 2017;56(7):e105-22.

38. Gosselink R, Langer D, Burtin C, Probst V, Hendriks HJM, van der Schans CP, et al. Clinical practice guideline for physical therapy in patients with COPD practice guidelines. Dutch J Phys Ther. 2008;118(suppl):1-60.

39. Langer D, Hendriks E, Burtin C, Probst V, van der Schans C, Paterson W, et al. A clinical practice guideline for physiotherapists treating patients with chronic obstructive pulmonary disease based on a systematic review of available evidence. Clin Rehabil. 2009;23(5):445-62

40. Sandland CJ, Singh SJ, Curcio A, Jones PM, Morgan MD. A profile of daily activity in chronic obstructive pulmonary disease. J Cardpulm Rehabil. 2005;25(3):181-3.

41. Pitta F, Troosters T, Spruit MA, Probst VS, Decramer M, Gosselink R. Characteristics of physical activities in daily life in chronic obstructive pulmonary disease. Am J Respir Crit Care Med. 2005;171(9):972-7.

42. Tabak M, Vollenbroek-Hutten $M$, van der Valk $P$, van der Palen J, Tönis T, Hermens $\mathrm{H}$. Telemonitoring of daily activity and symptom behavior in patients with COPD. Int J Telemed Appl. 2012;2012:438736.

43. Lores V, Garcia-Rio F, Rojo B, Alcolea S, Mediano O. Recording the daily physical activity of COPD patients with an accelerometer: an analysis of agreement and repeatability. Arch Bronconeumol. 2006;42(12):627-32.

44. Dale J, Connor S, Tolley K. An evaluation of the west surrey telemedicine monitoring project. J Telemed Telecare. 2003;9(Suppl 1):S39-41.

45. McCabe C, McCann M, Brady AM. Computer and mobile technology interventions for self-management in chronic obstructive pulmonary disease. Cochrane Database Syst Rev. 2017;5:CD011425.

\section{Ready to submit your research? Choose BMC and benefit from:}

- fast, convenient online submission

- thorough peer review by experienced researchers in your field

- rapid publication on acceptance

- support for research data, including large and complex data types

- gold Open Access which fosters wider collaboration and increased citations

- maximum visibility for your research: over $100 \mathrm{M}$ website views per year

At BMC, research is always in progress.

Learn more biomedcentral.com/submissions 